\title{
LAUDO DE ACESSIBILIDADE: QUESTÕES TÉCNICAS E METODOLOGIA DE PROJETO
}

\author{
SILVEIRA, Plínio Renan Gonçalves da; \\ Universidade Federal do Ceará |PPGAU + \\ $\mathrm{D} \mid$, Mestrando \\ e-mail:pliniorenan@gmail.com
}

\begin{abstract}
RESUMO
Estes artigo tem como objetivo lançar ao debate a questão dos laudos técnicos de acessibilidade. Procura explorar os aspectos técnicos, legais e de responsabilidade técnica que envolve a elaboração destes documentos, amparando-se na pesquisa bibliográfica e documental. Subsequentemente, através de um exercício de metodologia de projeto e de entrevistas semiestruturadas com arquitetos responsáveis por obras de reforma de acessibilidade, busca investigar o uso do laudo de acessibilidade como instrumento auxiliar com vistas a melhorar, através da sistematização de informações, o processo de planejamento destes projetos.
\end{abstract}

Palavras chave: laudo de acessibilidade; acessibilidade espacial; metodologia de projeto.

\begin{abstract}
This article aims to discuss the issue of technical accessibility reports. It seeks to explore the technical, legal and technical liability aspects involved in the preparation of these documents, based on bibliographical and documentary research. Subsequently, through an exercise of design methodology and semi-structured interviews with architects responsible for accessibility renovation works, it seeks to investigate the use of the accessibility report as an auxiliary tool with the aim of improving, through the systematization of information, the planning process of these projects.
\end{abstract}

Keywords: accessibility report; spatial accessibility; project methodology.

\section{INTRODUÇÃO}

As discussões acerca da inclusão de pessoas com deficiência assumem grande relevância no contexto brasileiro, onde, os sólidos instrumentos de promoção de acessibilidade normas e leis que inserem o país num patamar privilegiado - parecem não ter o devido rebatimento no ambiente construído, fazendo com que, em muitos casos, as pessoas com deficiência ainda pareçam ser invisíveis aos olhos da população sem deficiência. Esta invisibilidade e distanciamento da realidade destas pessoas finda por reverberar em barreiras atitudinais, sendo esta a geratriz de todas as outras barreiras.

Contraditoriamente, os números do Censo de 2010 apontaram 45.606 .048 milhões de pessoas no Brasil que declararam ter pelo menos uma das deficiências investigadas, correspondendo ao alarmante percentual de $23,9 \%$ da população brasileira. Paralelamente, os censos vêm apontando o crescente envelhecimento populacional no Brasil, ratificando 


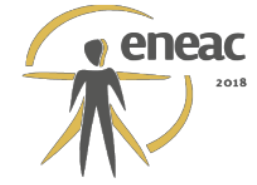

este que tem sido um fenômeno de escala global. O índice de envelhecimento populacional ${ }^{1}$ no Brasil saltou de 6,4 em 1960 para 30,7 em 2010, correspondendo a um aumento de $377,9 \%$. Os dados evidenciam a urgência da promoção de acessibilidade através de espaços inclusivos.

A suposta invisibilidade destas pessoas se dá quando os ambientes não oferecem plenas condições de mobilidade e acessibilidade para que possam ser usufruídos com segurança e autonomia, conforme prevê a regulação específica. A falta de acessibilidade contribui para que muitas destas pessoas permaneçam reclusas a espaços privados ou mesmo institucionais. Construir novos espaços e adaptar o ambiente construído, tomando como base os princípios do desenho universal, são urgências necessárias para permitir a usabilidade dos espaços pelo maior número possível de pessoas: pessoas com e sem deficiência, crianças, pessoas com mobilidade reduzida, incluindo idosos, pessoas obesas, gestantes, etc.

No âmbito da construção civil, é preciso ampliar as discussões sobre estas construções e reformas, estudar os métodos e as questões técnicas que permeiam as obras de acessibilidade, a fim de que possam contribuir para balizar os profissionais da área e viabilizar projetos verdadeiramente inclusivos. Neste aspecto, o laudo de acessibilidade, respaldado por um profissional habilitado (arquiteto ou engenheiro civil), torna-se um documento de relevância na medida em que possibilita atestar se os imóveis são de fato acessíveis a todas as pessoas, inclusive pessoas com deficiência. Contribuem ainda para a mudança efetiva do ambiente construído, pois engendram demandas por adaptações naqueles imóveis com pendências de acessibilidade.

Existem variações de tipos de laudo, desde aqueles que apenas atestam por extenso se um determinado imóvel é ou não acessível, até modelos mais completos, onde são listados todos os itens da edificação em desconformidade com a regulação específica, podendo ainda apresentar soluções de projeto, fotografias de cada caso, etc. Além das questões técnicas concernentes à elaboração destes documentos, especula-se que a capacidade de sistematização de informações do imóvel vistoriado, dos parâmetros de acessibilidade e da base legal, que podem estar presentes nos laudos, pode contribuir para a melhoria dos processos de planejamento de reformas de acessibilidade. Desta forma, podem oferecer um caminho metodológico, mesmo nos casos onde não haja demanda prévia para elaboração destes documentos.

\section{ACESSIBILIDADE E DESENHO UNIVERSAL}

A luta por direitos das pessoas com deficiência é antiga e repleta de importantes marcos internacionais ${ }^{2}$. A partir da metade do século $X X$, houve uma evolução exponencial do olhar sobre a questão da deficiência. Ao longo dos anos, o conceito de deficiência superou 0 "modelo médico", ligado à reabilitação e ao paradigma da "integração" na sociedade para uma visão mais holística e humanitária: o "modelo social", vinculado à equiparação de direitos e à efetiva inclusão social. Nos anos 1970, a Organização Mundial de Saúde (OMS) deu um primeiro passo que desvinculou a deficiência da Classificação Internacional de Doenças (CID). Posteriormente, com a aprovação da Resolução WHA54.21, passou a

\footnotetext{
${ }^{1}$ Quociente da população de 65 anos ou mais pela população com menos de 15 anos.

${ }^{2}$ Dentre eles podemos citar alguns documentos da ONU: Declaração Universal dos Direitos Humanos de 1948, Declaração dos Direitos das Pessoas Portadoras de Deficiências de 1975, Programa de Ação Mundial para as pessoas com deficiência de 1982 e a Convenção sobre os Direitos das Pessoas com Deficiência e seu Protocolo Facultativo de 2007 que foi incorporada à legislação brasileira em 2008. Também cabe citar a Convenção Interamericana para a eliminação de todas as formas de discriminação contra as Pessoas Portadoras de Deficiência e a Carta para o Terceiro Milênio, ambas de 1999 e o ADA - Americans with Disabilities Act de 1990.
} 


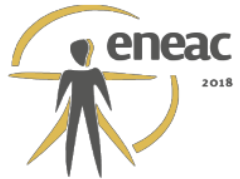

considerar nesta conceituação, entre outros fatores, a influência do ambiente em que a pessoa com deficiência está inserida (ORGANIZAÇÃO MUNDIAL DE SAÚDE, 2001).

Deste modo, o espaço passou a ser entendido como um agente ativo sendo capaz tanto de limitar como de ampliar o acesso e uso dos ambientes. Quando concebidos sem barreiras arquitetônicas, estes possibilitam o uso equitativo, independente das características ou habilidades individuais das pessoas. Segundo Cambiaghi (2007, p. 23) "quando uma pessoa com deficiência está em um ambiente acessível, suas atividades são preservadas, e a deficiência não afeta suas funções". Em caso contrário, porém concretiza-se aquilo que Duarte \& Cohen (1995) designaram de "Exclusão Espacial". Este conceito desenvolvido pelas autoras coloca o espaço como autor da exclusão, sendo este espelho das práticas segregatórias de uma sociedade.

As características do ambiente, portanto, assumem responsabilidade vital na questão da inclusão das pessoas com deficiência ou mobilidade reduzida. A acessibilidade é o vetor que viabiliza a inclusão destas pessoas no ambiente construído, bem como em diferentes aspectos da vida social, possibilitando assim a equiparação de oportunidades e a concretização da cidadania.

O conceito de acessibilidade também está em constante evolução na literatura e nas regulações específicas. $O$ art. $2^{\circ}$ da Lei $n .010 .098 / 2000$ (com redação atualizada pela Lei Brasileira de Inclusão no 13.146, de 2015 - 'L.B.I.') define acessibilidade como:

A possibilidade e condição de alcance para utilização, com segurança e autonomia, de espaços, mobiliários, equipamentos urbanos, edificações, transportes, informação e comunicação, inclusive seus sistemas e tecnologias, bem como de outros serviços e instalações abertos ao público, de uso público ou privados de uso coletivo, tanto na zona urbana como na rural, por pessoa com deficiência ou com mobilidade reduzida (BRASIL, 2015).

Atualmente, no que concerne ao espaço construído, o entendimento de acessibilidade está intrinsecamente ligado ao conceito desenho universal. Embora este termo tenha sido utilizado pela primeira vez nos Estados Unidos pelo arquiteto Ron Mace em 1985 ('Universal Design'), o conceito de desenho universal já era discutido desde os anos 1960, por exemplo, através dos termos "barrier-free design" e "design for all" (SANTIAGO, 2005).

O desenho universal pode ser definido como uma ideia abrangente de design de espaços, produtos e serviços desenvolvidos para o maior número de pessoas possível: pessoas com e sem deficiência, pessoas com baixa estatura, crianças, pessoas mobilidade reduzida, incluindo idosos, pessoas obesas, gestantes, lactantes ou com crianças de colo, etc. Desta forma, o desenho universal tem sido uma importante ferramenta para promover a acessibilidade espacial, na medida em que expande o conceito para todas as pessoas, inclusive pessoas com deficiência, e torna-a uma necessidade de todos.

Em 1997, o Centro de Desenho Universal da Universidade da Carolina do Norte sistematizou o conceito de desenho universal através de sete princípios, explanados abaixo:

Uso equitativo: trata-se de ambientes e produtos que permitem o uso igualitário ou equiparável, procurando atender às diferentes capacidades e possibilidades de uso; Estas soluções, porém não podem segregar um determinado grupo, devem ser iguais ou equivalentes. Exemplo: Portas automáticas com abertura por sensores que permitem acesso igualitário para todos.

Uso flexível: trata-se de ambientes e produtos que permitem o uso por pessoas com diferentes habilidades ou preferências, ou seja, adaptáveis às variadas formas de uso. Exemplo: tesouras que possibilitam o uso por pessoas destras e canhotas.

Uso simples e intuitivo: trata-se de ambientes e produtos de fácil entendimento, que sejam 


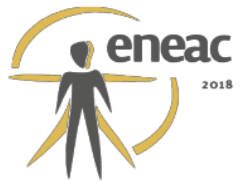

compreensíveis para qualquer pessoa, independente de sua experiência prévia de uso, da idade ou escolaridade, do domínio do idioma, do nível de concentração. Exemplo: Pictogramas de sinalização universais nos banheiros.

Informação perceptível: trata-se de ambientes e produtos capazes de fornecer a informação necessária, independente da capacidade sensorial do usuário. Estas soluções podem utilizar informações redundantes, ou seja, transmitidas através de duas formas: visual e tátil ou visual e auditiva ou auditiva e tátil. Exemplo: Alarmes "audiovisuais" que emitem sinais sonoros e luminosos.

Tolerância ao erro: trata-se de ambientes e produtos que se antecipam a uma possível situação de risco, oferecendo condições de segurança para todos. Exemplo: Pisos antiderrapantes em escadas, rampas ou em áreas molhadas.

Baixo esforço físico: trata-se de ambientes e produtos que permitem uso eficaz com o mínimo de esforço físico possível, abrangendo, portanto a maior gama de capacidades de uso. Exemplo: torneiras e maçanetas de alavanca.

Dimensionamento adequado: trata-se de ambientes e produtos com dimensões de uso abrangente, permitindo uso pela maior diversidade antropométrica possível, independente do tamanho, postura ou condição de mobilidade do usuário. Exemplo: Portas que permitem a passagem de cadeiras de rodas, cadeiras dimensionadas para pessoas obesas.

No Brasil, o desenho universal esteve em crescente debate a partir dos anos 1990 e foi incorporado na atualização da norma brasileira de acessibilidade NBR $9050^{3}$ da Associação Brasileira de Normas Técnicas (ABNT) em 1994, bem como na legislação brasileira através do Decreto Federal 5.296/2004, passando a subsidiar a concepção dos projetos arquitetônicos e urbanísticos no país. Mais recentemente, a Lei Brasileira de Inclusão da Pessoa com Deficiência no 13.146, de 2015 adotou o desenho universal como regra de caráter geral ${ }^{4}$ através do Artigo 55 que assim estabelece:

\begin{abstract}
A concepção e a implantação de projetos que tratem do meio físico, de transporte, de informação e comunicação, inclusive de sistemas e tecnologias da informação e comunicação, e de outros serviços, equipamentos e instalações abertos ao público, de uso público ou privado de uso coletivo, tanto na zona urbana como na rural, devem atender aos princípios do desenho universal, tendo como referência as normas de acessibilidade.
\end{abstract}

$\S 10$ O desenho universal será sempre tomado como regra de caráter geral.

$\S 20$ Nas hipóteses em que comprovadamente o desenho universal não possa ser empreendido, deve ser adotada adaptação razoável. (BRASIL, 2015).

É importante destacarmos que, como mostrado no $\S 2^{\circ}$ do Artigo 55 da LBI, existem casos específicos em que o desenho universal pode não oferecer condições equiparáveis a uma dada necessidade de um grupo ou indivíduo. Salientamos que, embora concebida de forma mais abrangente possível, a própria NBR 9050 considerou as medidas antropométricas entre $5 \%$ a $95 \%$ da população brasileira para determinação das dimensões referenciais.

Nestes casos extremamente particulares, a adaptação razoável se estabelece como possibilidade de intervenção específica, com vistas a promover a igualdade de

\footnotetext{
${ }^{3}$ Em 1985, a ABNT criou a primeira norma pertinente à acessibilidade espacial: "NBR 9050 - Adequação das edificações, equipamentos e mobiliário urbano à pessoa deficiente". Atualmente com a nomenclatura: "Acessibilidade a edificações, mobiliário, espaços e equipamentos urbanos", a NBR 9050/2015 orienta todos os projetos de intervenções em acessibilidade no país.

${ }_{4}^{4}$ A L.B.I. também introduziu no Capítulo I - Disposições gerais da Lei 10.098/2000 o conceito de desenho universal.
} 


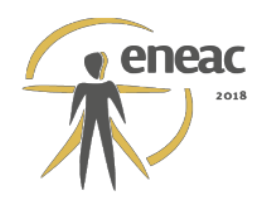

oportunidades. A Convenção sobre os Direitos das Pessoas com Deficiência da Organização das Nações Unidas (ONU), ratificada na legislação brasileira através do Decreto Legislativo nำ 186/2008 e promulgada através do Decreto ํㅜ 6.949/2009 define adaptação razoável como:

[...] as modificações e os ajustes necessários e adequados que não acarretem ônus desproporcional ou indevido, quando requeridos em cada caso, a fim de assegurar que as pessoas com deficiência possam gozar ou exercer, em igualdade de oportunidades com as demais pessoas, todos os direitos humanos e liberdades fundamentais (BRASIL, 2009).

A adaptação razoável consiste, portanto em adequações com soluções a mais individualizada possível, estendendo-se, portanto além da legislação e das normas técnicas, pois visa atender a uma necessidade específica em função de uma dada deficiência, para que se estabeleça a igualdade de oportunidades com as demais pessoas. (CONSELHO NACIONAL DO MINISTÉRIO PÚBLICO, 2016).

A evolução do conceito de acessibilidade e desenho universal, bem como as conquistas das lutas dos movimentos de pessoas com deficiência, contribuíram para a construção de uma regulação consistente. Atualmente, existem argumentos legais que exigem acessibilidade a todos os ambientes de edificações de uso público e privado de uso coletivo. A estruturação deste regimento, ao longo do tempo, repercutiu no aumento da fiscalização das edificações, no sentido de averiguar se estas cumprem os parâmetros estabelecidos para garantir acesso e uso para todas as pessoas, inclusive pessoas com deficiência. Neste contexto, o laudo de acessibilidade se estabelece como um dos instrumentos de fiscalização e análise destas edificações.

\section{LAUDO DE ACESSIBILIDADE: QUESTÕES TÉCNICAS}

Os laudos de acessibilidade são documentos técnicos produzidos a partir de vistorias cujo objetivo é diagnosticar uma data edificação em função dos parâmetros legais e normativos de acessibilidade. Além da legislação nacional, existem as legislações estaduais e municipais, devendo-se sempre aplicar aquela que apresenta aspectos mais restritivos. Via de regra, esta análise dos parâmetros normativos e legais de acessibilidade tem caráter conclusivo, apontando se o imóvel é ou não acessível, devendo ser respaldada por um profissional habilitado (arquiteto ou engenheiro civil) com 0 devido registro de responsabilidade técnica nos respectivos conselhos.

A necessidade da emissão destes documentos possui motivações diversas: avaliação prévia para possíveis investimentos em um determinado imóvel, determinação do Ministério Público ou prefeituras em função do não cumprimento das regulações de acessibilidade, obrigação legal (no caso de edifícios públicos, conforme determina a L.B.I.), entre outros.

Ressaltamos que o Decreto Federal 5.296/2004 estabeleceu prazos para regularizações de edifícios existentes (quando da publicação do Decreto) de uso público e coletivo. O prazo limite para adaptação de edificações de uso público existentes (em 2004) encerrou em junho de 2007, e para edificações de uso coletivo, em dezembro de 2008. Edificações construídas a partir de 2004 já teriam a obrigação legal de cumprir o Decreto. Desta forma, todas as edificações que se enquadram nestes usos no Brasil devem ser acessíveis. Em caso contrário, estão sujeitas a denúncias junto a órgãos de controle a fim de que sejam regularizadas.

Nos últimos anos, os Ministérios Públicos Federais e Estaduais têm se tornado importantes canais para garantia das condições de acessibilidade e demais direitos das pessoas com 


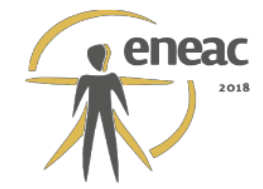

deficiência ${ }^{5}$ A partir de uma denúncia, o MP pode vir a instaurar um Inquérito Civil e providenciar vistorias técnicas de acessibilidade, requisitando o laudo de acessibilidade como documento técnico comprobatório daquela irregularidade ${ }^{6}$. Nestes casos, o laudo assume, portanto, este caráter de evidência, exigindo diligência e perícia do responsável técnico.

Quanto constatada a falta de acessibilidade de uma edificação, comprovada através do laudo técnico, é comumente celebrado um Termo de Ajustamento de Conduta - TAC, estipulando os prazos para a adequação, ou, quando esta celebração não é aceita por parte do investigado, é ajuizada uma Ação Civil Pública. (CONSELHO NACIONAL DO MINISTÉRIO PÚBLICO, 2016).

Quanto às edificações públicas, um novo paradigma surgiu com a Lei Brasileira de Inclusão da Pessoa com Deficiência no 13.146/2015, no sentido de intensificar o monitoramento e impulsionar a efetiva adequação dos espaços. O Art. 120 da Lei reza que:

Cabe aos órgãos competentes, em cada esfera de governo, a elaboração de relatórios circunstanciados sobre o cumprimento dos prazos estabelecidos por força das Leis no 10.048, de 8 de novembro de 2000, e no 10.098, de 19 de dezembro de 2000, bem como o seu encaminhamento ao Ministério Público e aos órgãos de regulação para adoção das providências cabíveis (BRASIL, 2015).

A partir daí, a Portaria Interministerial oㅡ 271 de 11 de maio de 2016 estabeleceu as diretrizes para os procedimentos de elaboração e publicação destes relatórios onde devem constar: lista orçamentária, laudo de acessibilidade, laudo padronizado através de formulário e plano de trabalho com as ações e reformas necessárias para efetivar a acessibilidade de cada edificação pública, dispostas em um cronograma de metas. As adaptações de acessibilidade foram então sistematizadas em três passos:
$1^{\circ}$ Elaboração de laudo de acessibilidade: Documento de análise e diagnóstico onde constam as conclusões sobre a conformidade da edificação às normas de acessibilidade e, no caso de correções que exijam intervenções mais complexas, indica os projetos necessários para adaptação.
$2^{\circ}$ Contratação de projetos (se necessário) e do orçamento da obra: Projetos indicados no laudo de acessibilidade e elaboração de quantitativos e orçamento dos serviços para orientação da reforma e da contratação dos serviços comuns de engenharia.
$3^{\circ}$ Contratação da execução dos Serviços Comuns de Engenharia: Contratação de empresa para efetiva execução dos serviços de adaptação do imóvel com realização de serviços comuns de engenharia. (MINISTÉRIO DA JUSTIÇA E CIDADANIA/ SECRETARIA ESPECIAL DOS DIREITOS DA PESSOA COM DEFICIÊNCIA, 2016).

Desta forma, a Lei instituiu a obrigatoriedade de elaboração de laudos de acessibilidade para todos os edifícios públicos. Este laudo constitui um documento pericial respaldado pela respectiva RRT ou ART do(s) profissional(ais) envolvidos, devendo ser encaminhado à Procuradoria Federal dos Direitos do Cidadão do Ministério Público Federal e publicado no sítio ou portal eletrônico do órgão ou entidade, conforme Artigo 10 da Portaria Interministerial ํㅡㄴ 271 de 11 de maio de 2016 .

\footnotetext{
${ }^{5}$ Outros órgãos federais atuantes na garantia dos direitos das pessoas com deficiência: Coordenadoria para Integração da Pessoa Portadora de Deficiência - CORDE e o Conselho Nacional de Defesa dos Direitos das Pessoas Portadoras de Deficiência - CONADE.

${ }^{6}$ Outros documentos comumente requisitados pelo MP são: Alvará de Construção ou Reforma, Alvará de Funcionamento ou da Licença de Operação, "Habite-se", Projeto arquitetônico da edificação, Registro de Responsabilidade Técnica (RRT) ou Anotação de Responsabilidade Técnica (ART).
} 


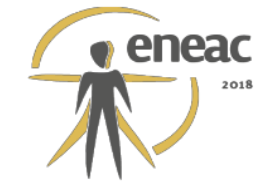

Outra inovação, trazida pela referida Lei, é a questão da lista orçamentária ou cesta-padrão. Através deste instrumento, pode-se estabelecer um orçamento prévio, através de uma lista disponibilizada em planilha onde constam os itens necessários para a execução das adaptações apontadas pelo laudo. Estes itens, em sua grande maioria, foram extraídos do Sistema Nacional de Pesquisa de Custos e Índices da Construção Civil (SINAPI), oferecendo assim um suporte ao planejamento orçamentário dos gestores.

Apesar do Decreto 5.296/2004 também ter determinado prazos para adaptações em edificações de uso coletivo, a L.B.I. não determinou a obrigatoriedade da elaboração de laudos para estes casos. Esta demanda surge, portanto, através de denúncias aos órgãos de controle ou como estudos de viabilidade. Nestes edifícios, o que inclui áreas comuns de edifícios residenciais, o que se observa na prática é um desconhecimento por parte dos responsáveis legais sobre as questões de acessibilidade e sua obrigatoriedade, o que contribui para a perenidade de espaços inacessíveis. Muitas vezes, as desconformidades de acessibilidade são apontadas por profissionais (engenheiros ou arquitetos) em inspeções prediais ${ }^{7}$. Salientamos que a "Norma de Inspeção Predial Nacional" do Instituto Brasileiro de Avaliações e Perícias de Engenharia (IBAPE) de 2012 e a Orientação Técnica OT003/2015-IBRAENG (Instituto Brasileiro de Auditoria de Engenharia) "Inspeção Predial e Auditoria Técnica Predial" trazem como recomendação a verificação do "Certificado de Acessibilidade" da edificação. Estes certificados, porém, são expedidos apenas por algumas prefeituras, a exemplo de São Paulo e Porto Alegre. Em cidades onde não há exigência ou emissão dos Certificados, o laudo técnico de acessibilidade poderá atestar se o edifício é ou não acessível.

\section{LAUDO DE ACESSIBILIDADE: METODOLOGIA DE PROJETO}

Esta seção traz os resultados da pesquisa acerca do uso do laudo de acessibilidade como instrumento auxiliar de projeto. Para tanto, convidamos três arquitetos para a realização de um exercício simples de metodologia de projeto em uma reforma de acessibilidade e, posteriormente, realizamos entrevistas semiestruturadas, a fim de apreender as impressões destes profissionais em relação ao exercício proposto. Com relação ao perfil dos entrevistados: o arquiteto A é servidor público de uma Universidade Federal e os arquitetos B e C trabalham em escritório próprio. Ressaltamos que todos os profissionais já realizam projetos de reforma de acessibilidade em sua prática profissional, portanto estão ambientados com as especificidades deste tipo de projeto. A partir da definição e aceitação dos participantes, deu-se o primeiro momento que consistiu no exercício metodológico.

\footnotetext{
${ }^{7}$ A ABNT NBR 5674/2012 intitulada: "Manutenção de edificações - Requisitos para o sistema de gestão de manutenção" que objetiva sistematizar os requisitos para a gestão do sistema de manutenção das edificações, aponta a necessidade das inspeções prediais periódicas e consequentemente dos relatórios de inspeção. As inspeções devem ser feitas atendendo aos intervalos constantes no manual elaborado conforme a ABNT NBR 14037 de 2011 (versão corrigida em 2014). Intitulada "Diretrizes para elaboração de manuais de uso, operação e manutenção das edificações - Requisitos para elaboração e apresentação dos conteúdos", a norma é responsável por criar uma interface entre a edificação / manutenção, através do manual de uso, operação e manutenção das edificações que deve ser elaborado e entregue pelo construtor e/ou incorporador da obra. Esta norma aponta a necessidade da realização de Laudos de Inspeção da Manutenção, Uso e Operação. Salienta-se que as vistorias devem seguir as diretrizes da NBR 13752/1996: "Perícias de engenharia na construção civil", que estabelece orientações e requisitos para estes procedimentos. O item 4.4 da NBR 13752/1996, que trata da questão da competência profissional estabelece que: " $A$ realização de perícias de engenharia na construção civil é matéria eminentemente técnica e de exclusiva competência de peritos e assistentes técnicos nos termos da legislação vigente" (ABNT,1996) e o item 6.3 que: "As perícias de engenharia na construção civil devem ser acompanhadas da ART (Anotação de Responsabilidade Técnica), conforme estabelece a Lei $n^{\circ}$ 6496/77" (ABNT,1996).
} 


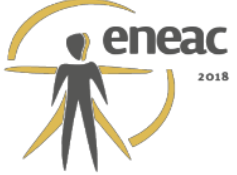

\subsection{Exercício metodológico}

Sugerimos aos projetistas, a partir de uma demanda de projeto de reforma de acessibilidade de sua prática profissional, que preenchessem um laudo de acessibilidade modelo antes de iniciar a fase de projetação. Os casos de reforma descritos pelos profissionais para realização do exercício foram:

Arquiteto A - Projeto de reforma de edifício educacional de dois pavimentos.

Arquiteto B - Projeto de reforma de edifício comercial térreo.

Arquiteto $\mathrm{C}$ - Projeto de reforma de clínica de dois pavimentos.

Este laudo modelo consiste na decomposição de todos os itens da NBR 9050/2015, bem como de outras normas e leis de acessibilidade, onde o profissional deveria sinalizar se a edificação cumpre ou não cada parâmetro e descrever brevemente caso a caso. Ao lado de cada item, deixou-se um espaço intitulado "Possíveis Soluções", onde o profissional deveria descrever brevemente como aquele determinado item poderia ser sanado e outro espaço destinado à inserção de fotografias que aludissem ao item em análise. Este laudo modelo (ver ANEXO) foi adaptado pelo autor a partir do laudo padrão disponibilizado pelo Ministério da Justiça e Cidadania/ Secretaria Especial dos Direitos da Pessoa com Deficiência. A ideia do modelo seria criar uma plataforma única que possibilitasse reunir todas as informações legais e normativas, cruzando-as com as informações situacionais dos imóveis, ilustrandoas com fotografias, e oferecendo ao projetista, portanto um guia prático dos itens que deveriam ser comtemplados no projeto de reforma.

Após a realização do exercício, que teve duração total de quatro meses, foram feitas as entrevistas semiestruturadas, a fim de apreender as impressões do uso deste instrumento na prática de projeto. Estas entrevistas foram gravadas e posteriormente transcritas pelo autor. As entrevistas partiram de três tópicos principais de discussão, cujos resultados serão abordados abaixo:

\subsection{Tópico 01 - Metodologia de projeto utilizada pelos profissionais}

Neste tópico inicial, questionamos sobre a metodologia de projeto já utilizada pelos profissionais para as reformas de acessibilidade. Os três arquitetos relataram um modo similar de trabalho, que seria a realização de um zoneamento na planta do imóvel. Este método consiste em setorizar as áreas de intervenção para posteriormente propor soluções para cada área demarcada. Os arquitetos também relataram que, em sua prática profissional, já houve casos em que primeiramente surgiu a demanda pela realização de um laudo e só depois houve a contratação do projeto. Destacamos, porém, que nos casos dos projetos realizados neste experimento não havia a demanda para realização prévia do laudo. $\mathrm{O}$ arquiteto $\mathrm{C}$ também relatou que: "a depender da complexidade do projeto, costumo fazer uma leitura dinâmica do sumário da NBR9050 para averiguar se estou comtemplando todos os itens. Para projetos mais simples já tenho memorizado boa parte dos parâmetros".

$\mathrm{O}$ arquiteto $\mathrm{B}$ relatou que a visita técnica possui importância fundamental para o desenvolvimento dos projetos de reforma em acessibilidade. Segundo o profissional, o registro adequado da visita técnica, principalmente quando acompanhado de levantamento arquitetônico é importante para a apreensão do objeto de estudo. Ele afirma que ficam muitas dúvidas sobre os itens existentes nos edifícios e que o uso de vídeos e fotos auxilia bastante durante a projetação.

De fato, o levantamento arquitetônico para reformas de acessibilidade exige um alto nível de precisão, pois as normas são bastante restritivas. Para o caso de sanitários, banheiros ou vestiários, por exemplo, a tolerância dimensional é de aproximadamente $10 \mathrm{~mm}$, de acordo 


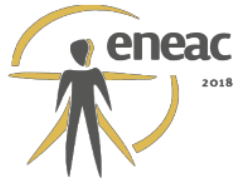

com a NBR9050/2015. Por este motivo, muitas vezes faz-se necessário o uso de instrumentos auxiliares, além das trenas: nível de mangueira (para medir diferenças de nível), inclinômetro (para medição de inclinação de rampas), dinamômetro (para medição de força em equipamentos), goniômetro (para medição de ângulos), luxímetro (para medição da intensidade da iluminação), decibelímetro (para medição do nível de pressão sonora), etc.

\subsection{Tópico 02 - A questão do tempo na utilização do laudo modelo de acessibilidade}

Quando questionados sobre a questão do gerenciamento do tempo do processo de planejamento, a partir do exercício proposto, os profissionais relataram maior gasto de tempo inicial para produzir o laudo, diferente de outros casos, onde poderiam partir diretamente para o projeto, após a prospecção das informações necessárias. Nosso exercício, porém, consiste exatamente em utilizar este tempo inicial para sistematização das informações, e mensurar os ganhos desta organização para a fase subsequente.

O gasto de tempo inicial foi visto, a princípio, como um fator negativo pelos profissionais, porém ao final do processo os arquitetos B e C estimaram, a partir de experiências com outros projetos, que o preenchimento do laudo não resultou em tempo adicional considerando o tempo global do processo. $O$ arquiteto $C$ relatou que, mesmo com o tempo adicional empregado para confecção do laudo, o tempo global do processo pode ter sido menor, quando comparado a outras experiências: "o laudo é composto de centenas de itens, então inicialmente existe um gasto maior de tempo, porém acredito que a organização dos itens permite agilizar a fase da projetação". O arquiteto A relatou que, devido à experiência na realização de muitos projetos similares, acredita que o tempo total do processo foi maior com a utilização do laudo modelo, porém que o processo pode ter resultado em um projeto de melhor qualidade.

\subsection{Tópico 03 - As possíveis implicações do uso do laudo para a prática do projeto}

Quando questionados sobre as implicações no uso do laudo de acessibilidade modelo como ferramenta auxiliar na prática de projeto de reforma de acessibilidade, os três profissionais relataram maior otimização do processo devido à sistematização dos dados no documento enviado. O arquiteto A assim relatou: "acredito que essa organização tenha resultado em um projeto mais completo, de melhor qualidade, pois nada escapa ao checklist do laudo. Ele segue item a item das normas". Sobre este mesmo ponto, o arquiteto C assim relatou: "embora já trabalhe com reformas deste tipo, são muitos itens de acessibilidade em várias normas que estão inclusive em constante atualização. Muitas vezes é difícil organizar todos os itens necessários". O Arquiteto C também apontou que, em alguns casos, a necessidade de realização do laudo precede o projeto, por exemplo, quando imposto pelo Ministério Público ou algum outro órgão de controle e conclui: "quando isso ocorre nota-se que, de fato, o processo de projeto torna-se mais funcional".

$\mathrm{O}$ arquiteto $\mathrm{B}$ destacou a importância da descrição prévia das soluções de projeto, dispostas na sessão "Possíveis soluções" do laudo (ver ANEXO). Segundo o profissional, esta rápida análise pode examinar a viabilidade de determinadas soluções ou sua impraticabilidade ${ }^{8}$, podendo ser levada para discussão com o cliente.

\footnotetext{
${ }^{8}$ A NBR 9050/2015 define impraticabilidade como "condição ou conjunto de condições físicas ou legais que possam impedir a adaptação de edificações, mobiliário, equipamentos ou elementos à acessibilidade" (ABNT, 2015). Esta, porém prescinde de uma justificativa técnica.
} 


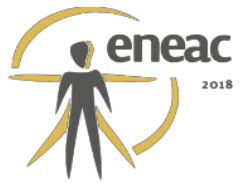

Outro ponto destacado pelo arquiteto $B$ diz respeito às imagens. $O$ profissional relatou que: "a sistematização fotográfica vinculada aos itens da norma também auxilia bastante na organização mental do projeto, pois nos remete imediatamente à situação prática". O Arquiteto A também relatou: "acho que a vantagem desse modelo de laudo seria exatamente na visualização das informações numa só interface".

\section{CONSIDERAÇÕES FINAIS}

Após a publicação do Decreto 5.296/2004, estipularam-se prazos para adaptações de todos os imóveis de uso público ou coletivo no Brasil. Esta obrigatoriedade de espaços acessíveis originou uma série de demandas por reformas visando à regularização a partir do cumprimento de inúmeros parâmetros normativos e legais de acessibilidade, bem como de documentos comprobatórios que atestassem a acessibilidade num dado imóvel. Estes documentos são frequentemente solicitados por determinação de órgãos de controle, como os Ministérios Públicos e as prefeituras. Os laudos de acessibilidade são documentos produzidos a partir de vistorias técnicas, onde geralmente são confrontados todos os itens da edificação com a extensa regulação de acessibilidade e cujo objetivo final é atestar se uma data edificação é ou não acessível. O laudo de acessibilidade, enquanto análise prévia em relação à fase de projeto, também pode ser usado como estudo de viabilidade para determinados empreendimentos. Destaca-se ainda a obrigatoriedade na elaboração dos laudos para o caso de edificações públicas, imposta pela Lei Brasileira de Inclusão da Pessoa com Deficiência no 13.146/2015.

Procuramos, através deste artigo, demonstrar que os laudos de acessibilidade podem assumir grande relevância também na questão metodológica de projeto de reforma de acessibilidade. Este procedimento, embora demande um tempo adicional na fase inicial do processo, oferece um guia objetivo dos itens a serem corrigidos, podendo conter ainda possíveis soluções técnicas para adequação de cada parâmetro normativo ou legal em desconformidade numa dada edificação, bem como a sistematização de imagens referenciadas. Através de um exercício metodológico a partir de um laudo modelo desenvolvido para esta pesquisa e de entrevistas semiestruturadas com os profissionais participantes, destacamos que a sistematização de informações que podem estar presentes no laudo técnico representa uma otimização do processo de planejamento de reformas de acessibilidade.

A partir destas considerações, conclui-se que o laudo de acessibilidade constitui um input importante no processo de projetação destas reformas, cuja complexidade envolve o cumprimento de uma extensa regulação, ainda que este não tenha sido demandado numa fase anterior. Sugere-se, portanto, que o laudo possa ser utilizado como uma ferramenta auxiliar, permitindo ao projetista maior segurança e proporcionando projetos de melhor qualidade.

\section{REFERÊNCIAS BIBLIOGRÁFICAS}

ASSOCIAÇÃO BRASILEIRA DE NORMAS TÉCNICAS. NBR 13752: Perícias de engenharia na construção civil. ABNT, 1996.

NBR 14037. Diretrizes para elaboração de manuais de uso, operação e manutenção das edificações - Requisitos para elaboração e apresentação dos conteúdos. ABNT, 2011.

. NBR 5674. Manutenção de edificações - Requisitos para o sistema de gestão de manutenção. ABNT, 2012 


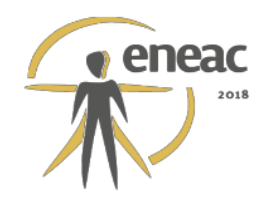

NBR 9050. Acessibilidade a edificações, mobiliário, espaços e equipamentos urbanos. Rio de janeiro: ABNT, 2015.

BRASIL. Lei 10.098, de 19 de dezembro de 2000, que estabelece normas gerais e critérios básicos para a promoção da acessibilidade das pessoas portadoras de deficiência ou com mobilidade reduzida, e dá outras providências. Brasília, DF, 2000.

Decreto № 5.296, de 2 de dezembro de 2004, que regulamenta as Leis ํㅗ 10.048 , de 8 de novembro de 2000, e 10.098, de 19 de dezembro de 2000. Brasília, DF, 2004.

Decreto no 6.949/2009, de 25 de agosto de 2009, que Promulga a Convenção Internacional sobre os Direitos das Pessoas com Deficiência e seu Protocolo Facultativo, assinados em Nova York, em 30 de março de 2007.

Lei Brasileira de Inclusão da Pessoa com Deficiência (Estatuto da Pessoa com Deficiência) no 13.146 de 06 de julho de 2015. Brasília, DF, 2015.

Portaria Interministerial no 271 de 11 de maio de 2016. Brasília, DF, 2016.

CAMBIAGHI, Silvana. Desenho universal: métodos e técnicas para arquitetos e urbanistas. São Paulo: Editora Senac São Paulo, 2007.

CONSELHO NACIONAL DO MINISTÉRIO PÚBLICO. Guia de atuação do Ministério Público: pessoa com deficiência: direito à acessibilidade, ao atendimento prioritário, ao concurso público, à educação inclusiva, à saúde, à tomada de decisão apoiada e à curatela. Brasília, 2016.

DUARTE, Cristiane Rose; COHEN, Regina. Segregação e Exclusão Sócio-Espacial: A questão dos Portadores de Deficiência Física. In: IV ENCONTRO NACIONAL DA ANPUR-UNB, 1995, Brasília. Anais do IV Encontro Nacional da ANPUR. 1995.

INSTITUTO BRASILEIRO DE AUDITORIA DE ENGENHARIA. Orientação Técnica OT-003/2015 Inspeção Predial e Auditoria Técnica Predial. IBRAENG, 2015.

INSTITUTO BRASILEIRO DE AVALIAÇÕES E PERÍCIAS DE ENGENHARIA. Norma de Inspeção Predial Nacional. IBAPE, 2012.

INSTITUTO BRASILEIRO DE GEOGRAFIA E ESTATÍSTICA. Censo Demográfico 2010. Rio de Janeiro: IBGE, 2012.

MINISTÉRIO DA JUSTIÇA E CIDADANIA/ SECRETARIA ESPECIAL DOS DIREITOS DA PESSOA COM DEFICIEENCIA. Manual de Adaptações de Acessibilidade, contendo o laudo padrão e a cesta padrão. Brasília, 2016.

ORGANIZAÇÃO DAS NAÇÕES UNIDAS (ONU). Convenção sobre os direitos das pessoas com deficiência e Protocolo Facultativo. Nova York, 2007.

ORGANIZAÇÃO MUNDIAL DA SAÚDE (OMS). WHA54.21 International classification of functioning, disability and health. Geneva, 2001; Disponível em: < http://apps.who.int/gb/archive/e/e_wha54.html>. Acesso em: 08 jul. 2017.

SANTIAGO, Zilsa Maria Pinto. Acessibilidade física no ambiente construído: o caso das escolas municipais de ensino fundamental de Fortaleza - CE (1990 - 2003). Dissertação de Mestrado FAUUSP. São Paulo, 2005. 
eneac

(1)

和

7. ANEXO: RECORTE DO MODELO DE LAUDO UTILIZADO NA PESQUISA

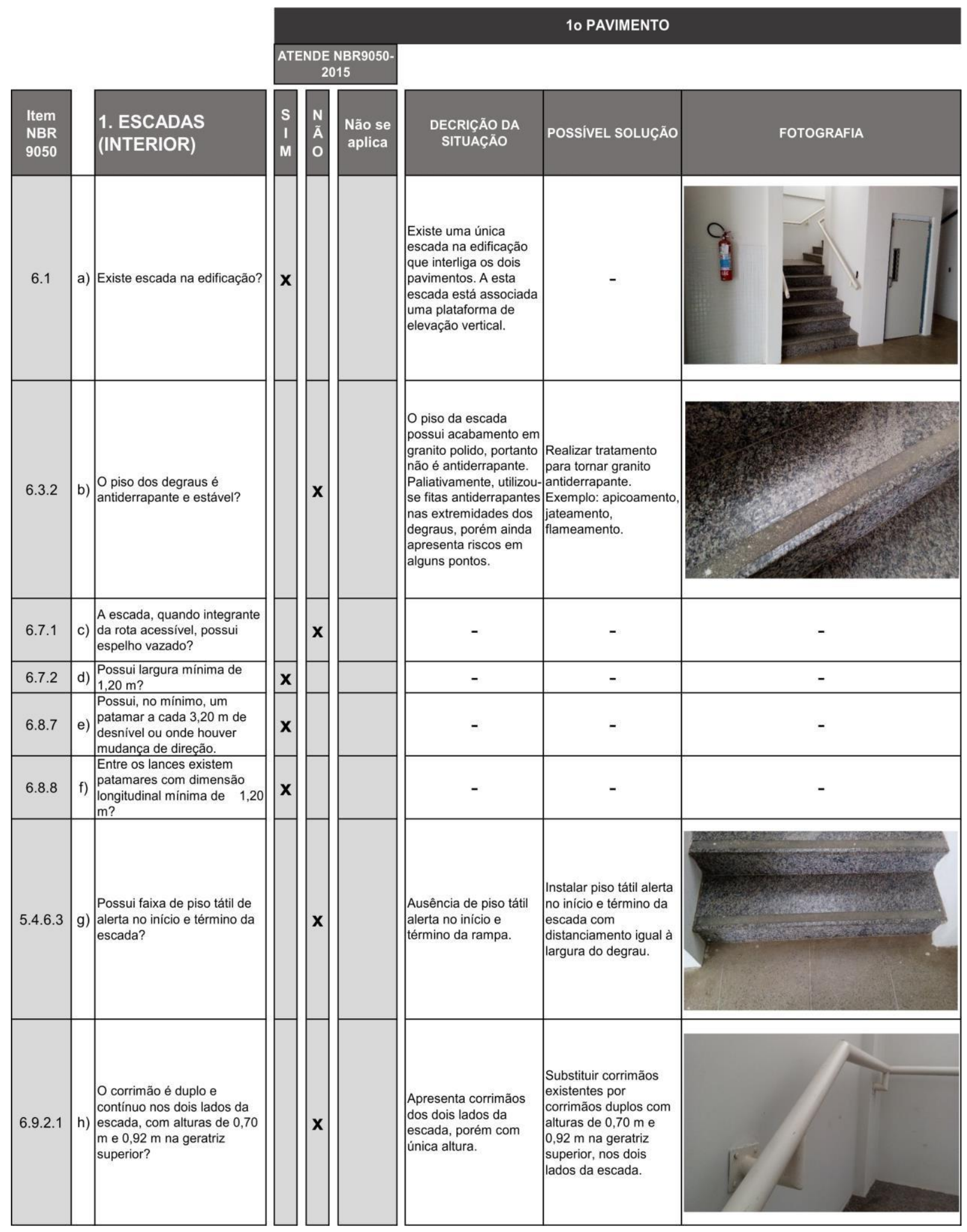

